\title{
Putrescine as a source of instant energy in the small intestine of the rat
}

\author{
S Bardócz, G Grant, D S Brown, A Pusztai
}

\begin{abstract}
Background and aims-It has been suggested that putrescine acts as a growth factor in the gut, but its exact function in some aspects of cellular metabolism is still in question. The aim of the present work was to identify some functions of putrescine in small bowel metabolism.

Animals-Rats (about $80 \mathrm{~g}$ ), in groups of five, were given either phytohaemagglutinin- or lactalbumin-containing diets, fed ad libitum or were fasted for 48 hours and re-fed for six or twelve hours before being killed.

Methods-Uptake of intraperitoneally or intragastrically administered $\left[{ }^{14} \mathrm{C}\right] \mathrm{pu}-$ trescine and its conversion to succinate by the rat small bowel mucosa was measured. Tissue polyamine and succinate contents were measured by high performance liquid chromatography and amino acid analysis respectively.

Results-Uptake of putrescine by the small bowel mucosa from the systemic circulation and conversion of about $30 \%$ of this to succinate occurs in the epithelium of the healthy small bowel. Compared with rats given food ad libitum, putrescine uptake was doubled in fasted animals and more than $70 \%$ of it was converted to succinate. All these changes returned to control values on refeeding. Using phytohaemagglutinin induced gut growth as a model, the uptake of putrescine from the systemic circulation by the serosal side of the small intestinal epithelium was increased immediately after growth was stimulated. During phytohaemagglutinin induced growth of the gut, putrescine was converted to succinate in the same proportion as in the healthy small bowel.

Conclusions-The experiments identified a novel function for putrescine in gut metabolism: it can be used as an instant energy source when required. (Gut 1998;42:24-28)
\end{abstract}

The Rowett Research Institute, Greenburn Road, Bucksburn, Aberdeen AB21 9SB, UK

S Bardócz

G Grant

D S Brown

A Pusztai

Correspondence to: Dr S Bardócz.

Accepted for publication 26 August 1997 phytohaemagglutinin; succinate; basolateral uptake; small bowel

Polyamines (putrescine, spermidine, and spermine) play a number of roles in human cellular metabolism. They are involved in nearly every step of DNA, RNA, and protein synthesis and are thus essential for cell proliferation, ${ }^{1-3}$ and there is evidence to suggest that they are intimately engaged in the control of cell growth. ${ }^{1-4}$ Cellular concentration of polyamines varies according to the stage of the cell cycle and one of the first steps in cell proliferation is the induction of ornithine decarboxylase (ODC; EC 4.1.1.17), the first enzyme of polyamine synthesis, an event that precedes both nucleic acid and protein synthesis. ${ }^{56}$ It is also possible that polyamines are required in a series of hitherto undetermined cellular processes.

In mammals the small intestine has one of the highest metabolic rates and proliferative activity of all tissues. Since the surface epithelium is renewed every $2-3$ days, polyamines are especially important for the constant cell division in the crypts of the Lieberkuhne of the normally functioning gut.

Putrescine, a diamine which is the decarboxylation product of ornithine in mammals, is the precursor of spermidine and spermine. It is a growth factor for the gut, ${ }^{78}$ and, together with spermidine and spermine, is necessary for its adaptive growth, ${ }^{9-13}$ but its other functions in the gut epithelium are still not clear.

Putrescine can be catabolised by acetylation and oxidation or, more often, just oxidised to $\gamma$-aminobutyric acid ${ }^{14-18}$ (GABA) by diamine oxidase (DAO; EC 1.4.3.6) and to succinate. ${ }^{14}{ }^{17}$

The localisation of putrescine and ODC in the small intestinal mucosa is surprising: ODC activity is higher and more putrescine is found in the non-proliferating epithelial cells of the villi than in the crypts where polyamines would be needed for the synthesis of spermidine and spermine. ${ }^{19}$ The localisation of DAO, an enzyme that is often used as a maturation marker for the gut epithelium, ${ }^{131618}$ is very similar to that of ODC. ${ }^{14}{ }^{18-20}$ The distribution of DAO, ${ }^{18} 19$ which catabolises putrescine, is difficult to reconcile with the physiological function of putrescine as a precursor for polyamine synthesis.

Therefore the aim of the present paper was to find out more about the possible role of putrescine in the small intestine and follow the fate of radiolabelled putrescine in two model systems. These are the adaptational gut growth induced by phytohaemagglutinin (PHA, the lectin from kidney bean Phaseolus vulgaris) and refeeding after fasting. In both of these models the growth of the gut is fully reversible. ${ }^{21}$
Materials and methods

All chemicals used were of the purest analytical grade from Sigma (UK). $\left[{ }^{14} \mathrm{C}\right]$ Putrescine was obtained from Amersham International, UK.

Thirty day old male Hooded-Lister specified pathogen-free rats of the Rowett colony (about $80 \mathrm{~g}$ ), kept singly in cages, were pre-fed ( $6 \mathrm{~g} / \mathrm{rat}$ per day) a semisynthetic highly digestible protein-containing and nutritious diet, 
supplemented with all recommended vitamins and minerals, containing lactalbumin as a protein source (LA; $100 \mathrm{~g} / \mathrm{kg}$ diet: control diet) for three days. They had access to distilled water ad libitum.

\section{EXPERIMENT 1}

Rats (groups of five) were kept on the control diet for three days. After an overnight fast, each rat was given $1.5 \mathrm{~g}$ of the diet. This feeding was necessary because the hormonal balance of the body (insulin, blood glucose concentrations, etc) is influenced by the time elapsed between the last meal and death, and might also affect the concentrations and distribution of putrescine. Immediately after this was eaten (about two minutes), they were given by either intragastric intubation or intraperitoneal (i.p.) injection a standard amount of $\left[{ }^{14} \mathrm{C}\right]$ putrescine $\left(8.5 \mathrm{nmol} ; 2.4 \times 10^{6} \mathrm{dpm} / \mathrm{rat}\right)$ in phosphate buffered saline. ${ }^{17}$ The $1.5 \mathrm{~g}$ of diet was also needed as a bolus of food, to accompany the $\left[{ }^{14} \mathrm{C}\right]$ putrescine. For the luminal uptake studies the rats were killed at 30 minute intervals (up to three hours) after intragastric intubation. For the basolateral uptake studies the rats were killed exactly 60 minutes after injection. This time point was based on the results of pilot studies which showed that putrescine uptake by the gut was linear, and the distribution of radioactivity between the organs did not change between 30 and 90 minutes after injection (data not given).

EXPERIMENT 2

Rats (groups of five) were fed on either the semisynthetic lactalbumin-containing diet or a diet in which $5 \%$ of the lactalbumin was replaced by kidney bean proteins, providing 42 mg PHA/rat per day. ${ }^{21}$ Half the rats on each of these diets were given, in their diet, a daily dose of $6 \mathrm{mg}$ of aminoguanidine (AG). They were also injected i.p. with $5 \mathrm{mg}$ AG in saline every day for three days. The other rats were injected with saline only. On the last day and after an overnight fast all rats were given $1.5 \mathrm{~g}$ of their respective diets. As soon as this was eaten (about two minutes), they were injected i.p. with $8.5 \mathrm{nmol}\left(2.4 \times 10^{6} \mathrm{dpm} / \mathrm{rat}\right)$ of $\left[{ }^{14} \mathrm{C}\right]$ putrescine and killed exactly one hour later.

EXPERIMENT 3

Rats (groups of five) were fasted for $48 \mathrm{~h}$ and re-fed ad libitum for six or twelve hours with the control diet. They were injected i.p. with $8.5 \mathrm{nmol}\left[{ }^{14} \mathrm{C}\right]$ putrescine and killed exactly one hour later.

METHODS

In all experiments rats were killed by halothane overdose. Their small intestines were removed, washed with ice-cold saline, and cut into segments as described previously. ${ }^{17}$ The luminal contents were collected and the radioactivity counted. The amount of radiolabel originating from putrescine was counted and calculated from the radioactivity measured in the different segments of the small intestine and blood. ${ }^{17}$ The polyamine content of the small intestinal tissue was analysed by high performance liquid chromatography (HPLC). ${ }^{22}$ To study the distribution of radioactivity in the polyamines, $18 \mathrm{~cm}$ segments of the jejunum, starting $7 \mathrm{~cm}$ and ending $25 \mathrm{~cm}$ distal to the pylorus end, were homogenised in $2 \%$ perchloric acid and centrifuged. A sample of the supernatant $(450 \mu \mathrm{l}$, containing 1800-3000 dpm) was analysed by HPLC to identify the radioactive polyamines or their derivatives. Fractions (45) were collected per sample and the radioactivity measured.

Succinate content was measured by an amino acid analyser with MS detector following the method of Womersley et al. ${ }^{23}$ Succinate concentration was calculated from the recorder traces of the standard and sample ultraviolet light absorbance.

\section{STATISTICAL ANALYSIS}

The results were subjected to one way analysis of variance using the Minitab computer program (Penn State University, USA). When $\mathrm{p}<0.05$, the significance between groups was estimated by Student's $t$-test.

\section{ANIMAL CARE}

All management and experimental procedures in this study were carried out in strict accordance with the requirements of the UK Animals (Scientific Procedures) Act 1986 by staff licensed under this act to carry out such procedures.

\section{Results}

To establish the role and fate of putrescine in the small bowel, putrescine metabolism and uptake were compared in small intestines from healthy intensively growing and fasting rats. The ability of the small bowel to absorb putrescine from either the gut lumen or systemic circulation was determined by giving a single dose of $8.5 \mathrm{nmol}\left[{ }^{14} \mathrm{C}\right]$ putrescine either intragastrically or i.p. Polyamine content of the jejunum was measured by HPLC and the radioactivity associated with putrescine and succinate was counted.

Table 1 shows radioactivity accumulated as $\left[{ }^{14} \mathrm{C}\right]$ putrescine and its metabolites in the jejunum and small bowel of healthy rats from Experiment 1. Table 2 gives counts originating from putrescine and present as either putrescine or succinate exactly one hour after administration. Radioactivity in the body continued to increase during the three hour observation period (data not given), while the label counted in the small bowel tissue reached its maximum between 90 and 120 minutes (table 1). When putrescine was given by intragastric intubation, after one hour about $25 \%$ of the total dose of radioactivity was found in the body and no conversion of putrescine to succinate was detected in the serum/blood. Some $10 \%$ of the counts were in the small intestinal tissue, but only $11-15 \%$ of that was retained in its original form: most of the label $(70 \%)$ was converted to succinate (table 2). One hour after i.p. injection of $\left[{ }^{14} \mathrm{C}\right]$ putrescine about $10 \%$ of the radioactivity given was confined to the small bowel (table 1), with about one third of it still present as putrescine and a similar quantity 
Table 1 Accumulation of radiolabel originating form $\left[{ }^{14} \mathrm{C}\right]$ putrescine incorporated into the jejunum or small intestine in relation to the dose of the whole body

\begin{tabular}{lccc}
\hline \multicolumn{5}{c}{${ }^{14}$ C label } \\
\cline { 2 - 3 } Time (min) & fejunum $^{\star}$ (pmol) & Small intestinal tissue (pmol) & Whole bodyt (nmol) \\
\hline After intragastric intubation & & \\
30 & $107(24)$ & $759(258)(8.9 \%)$ & $1.87(0.93)(22 \%)$ \\
60 & $118(63)$ & $870(115)(10.2 \%)$ & $2.04(0.76)(24 \%)$ \\
90 & $247(82)$ & $1307(132)(15.4 \%)$ & $3.06(0.42)(36 \%)$ \\
120 & $215(67)$ & $1598(281)(18.8 \%)$ & $2.38(0.51)(28 \%)$ \\
150 & $146(24)$ & $1179(165)(13.9 \%)$ & $1.44(0.17)(17 \%)$ \\
180 & $90(21)$ & $619(244)(7.3 \%)$ & $0.68(0.25)(8 \%)$ \\
After intraperitoneal injection & & & \\
60 & $167(13)$ & $582(98)(6.8 \%)$ & $7.91(0.25)(97 \%)$ \\
\hline
\end{tabular}

Data represent mean (SD) for five rats per treatment.

$\star 5-25 \mathrm{~cm}$ segment from the pylorus.

†Excluding small bowel.

Table $2{ }^{14} \mathrm{C}$ label recovered in the jejunum $(20 \mathrm{~cm})$ as putrescine and succinate one hour after luminal (for comparison) or systematic application of putrescine

\begin{tabular}{|c|c|c|c|c|}
\hline & \multicolumn{4}{|c|}{$\left[{ }^{14} C\right]$ putrescine recovered as } \\
\hline & \multicolumn{2}{|l|}{ Putrescine } & \multicolumn{2}{|l|}{ Succinate } \\
\hline & $\mathrm{nmol} / 20 \mathrm{~cm}$ & $\%$ & $\mathrm{nmol} / 20 \mathrm{~cm}$ & $\%$ \\
\hline Luminal & $0.94-1.28$ & $11-15$ & $5.18-5.70$ & $61-67$ \\
\hline Intraperitoneal & $2.72-2.81$ & $32-33$ & $2.72-3.15$ & $32-37$ \\
\hline LA, i.p. & $2.78-2.81$ & $32-33$ & $2.72-2.81$ & $32-33$ \\
\hline $\mathrm{LA}+\mathrm{AG}$, i.p. & $8.41-8.50$ & $99-100^{\star \star}$ & $0-0.43$ & $0-5^{\star \star}$ \\
\hline PHA, i.p. & $2.04-2.13$ & $24-25$ & $3.06-4.17$ & $36-49$ \\
\hline $\mathrm{PHA}+\mathrm{AG}$, i.p. & $8.41-8.50$ & $98-100^{\star \star}$ & $0-0.26$ & $0-3^{\star \star}$ \\
\hline Ad libitum, i.p. & $2.76-2.81$ & $32-35$ & $2.98-3.49$ & $35-41$ \\
\hline $48 \mathrm{~h}$ fast, i.p. & $0.18-0.26$ & $2-3^{\star \star}$ & $7.06-7.68$ & $83-88^{\star \star}$ \\
\hline $6 \mathrm{~h}$ re-fed, i.p. & $0.09-0.34$ & $1-4^{\star \star}$ & $5.78-6.80$ & $68-80^{\star \star}$ \\
\hline $12 \mathrm{~h}$ re-fed, i.p. & $0.94-1.02$ & $11-12^{\star \star}$ & $4.68-5.53$ & $55-65^{\star \star}$ \\
\hline
\end{tabular}

Data represent the range for two samples analysed.

LA, lactalbumin based control diet, containing $10 \%$ protein; PHA, kidney bean based diet, in which $5 \%$ of the lactalbumin was replaced by bean proteins, providing $42 \mathrm{mg} \mathrm{PHA} / \mathrm{rat}$ per day; AG, LA or PHA diets containing $6 \mathrm{mg}$ aminoguanidine/day. Rats in these groups were also injected intraperitoneally (i.p.) with $5 \mathrm{mg}$ aminoguanidine in saline every day for three days.

${ }^{\star}$ Significantly different $(\mathrm{p}<0.01)$ from LA or ad libitum.

Table 3 Changes in polyamine content of the rat jejunum after three days of treatment

Polyamine content $(\mathrm{nmol} / 20 \mathrm{~cm})$

\begin{tabular}{lccc} 
& Putrescine & Spermidine & Spermine \\
\hline LA & $90(10)$ & $493(13)$ & $387(8)$ \\
LA + AG & $642(206)^{\star}$ & $505(19)$ & $401(13)$ \\
PHA & $350(152)^{\star}$ & $694(41)^{\star}$ & $709(10)^{\star}$ \\
PHA + AG & $787(398)^{\star}$ & $490(41)$ & $506(9)^{\star}$ \\
Pooled SD & 192 & 29 & 10 \\
Ad libitum & $137(38)$ & $726(49)$ & $389(27)$ \\
48 h fast & $28(5)^{\star \star}$ & $504(24)^{\star \star}$ & $199(11)^{\star \star}$ \\
6 h re-fed & $82(17)^{\star}$ & $557(16)^{\star}$ & $218(10)^{\star \star}$ \\
12 h re-fed & $163(21)$ & $647(38)$ & $221(12)^{\star \star}$ \\
Pooled SD & 20 & 32 & 15 \\
\hline
\end{tabular}

Data are means (SD) for five rats per treatment.

LA, lactalbumin based control diet, containing $10 \%$ protein; PHA, kidney bean based diet, in which $5 \%$ of the lactalbumin was replaced by bean proteins, providing $42 \mathrm{mg} \mathrm{PHA} / \mathrm{rat}$ per day; AG, LA or PHA diets containing $6 \mathrm{mg}$ aminoguanidine/day. Rats in these groups were also injected intraperitoneally with $5 \mathrm{mg}$ aminoguanidine in saline every day for three days.

Significantly different from LA or ad libitum fed rats: ${ }^{\star} \mathrm{p}<0.05 ;{ }^{\star \star} \mathrm{p}<0.01$.

metabolised to succinate (table 2). The results also indicate that DAO, which can be considered as a maturation marker enzyme, ${ }^{13} 1618$ works more efficiently on putrescine taken up from the gut lumen than from the circulation. In the jejunum under normal conditions putrescine accounts for about $9-10 \%$ of tissue polyamine content (table 3 ).

On the basis of analysis in two jejunal samples, in ad libitum fed rats the succinate pool of the jejunal mucosa is about 1475 $\mathrm{nmol} / 20 \mathrm{~cm}$, about $3 \%$ of which (44 nmol) originates from putrescine.

To study alterations in putrescine metabolism during intensive growth of the small bowel, the PHA model was used. ${ }^{23}$ In this model, uptake of putrescine from the basolateral side was stimulated within 60 minutes of intestinal growth being stimulated by PHA (table 4). By the third day of treatment, tissue putrescine content was significantly elevated (table 3), but the proportion of radioactivity recovered as putrescine was reduced (table 2). To prove that the increase in putrescine content did indeed result from decreased DAO activity, ${ }^{16}$ some of the rats were treated with AG, a specific inhibitor of DAO. Not surprisingly, it appeared that less putrescine was taken up from the circulation via the basolateral membrane into the small bowel resulting in higher tissue putrescine contents (table 3 ). At the same time all the label was recovered in the putrescine form and practically none found in succinate (table 2).

The polyamine content of the small bowel of rats fasted for 48 hours was very significantly decreased compared with that in animals fed ad libitum. When the rats were re-fed, the jejunal tissue polyamine content significantly increased (table 3), as has been reported by others. ${ }^{18}{ }^{23}$ However, in spite of a decrease in putrescine concentrations in the small intestine, putrescine uptake from the circulation via the basolateral side was highly significantly increased (table 4 ), and more than $80 \%$ was immediately converted to succinate with only traces retained as putrescine (table 2). However, during refeeding, as with the increase in putrescine content (table 3), putrescine uptake slowly returned to normal (table 4) and more of the radiolabel was retained as putrescine (table 2).

In blood, the putrescine concentrations were relatively constant (table 4) and, independent of the treatment, were maintained in a twofold concentration range.

\section{Discussion}

As polyamines have important and diverse roles in many facets of cellular activity (and because of the diversity of their roles in cellular metabolism), polyamine requirements are particularly high in rapidly growing tissues ${ }^{1-3}$ such as the small intestine..$^{722} 24$ In spite of the undoubted importance of polyamines in growth, little information is available on some of their functions in cellular metabolism. Since inhibition of polyamine biosynthesis does not prevent adaptive growth, extracellular polyamines may also be involved in the regulation of growth, with tissue needs for polyamines being only partially met by in situ synthesis. Stimulation by growth signals of polyamine uptake from the circulation via the basolateral membrane of the rat small intestine is partially responsible for the increase in small bowel polyamine pool size. ${ }^{26}$

Putrescine is a growth factor for the rat gut and may be directly involved in stimulation of epithelial DNA, RNA, and protein synthesis. ${ }^{78}$ However, on the basis of evidence in this paper, it may have an essential function in the small intestine: by forming succinate via GABA, it may serve as a source of instantly metabolisable 
Table 4 Blood polyamine concentrations and accumulation of radiolabel originating from $\left[{ }^{14} \mathrm{C}\right]$ putrescine incorporated into the jejunum or small intestine one hour after intraperitoneal injection of $\left[{ }^{14} \mathrm{C}\right]$ putrescine

\begin{tabular}{llll}
\hline \multirow{2}{*}{ Treatment } & \multicolumn{1}{c}{${ }^{14} \mathrm{C}($ pmol) } & \multicolumn{1}{c}{$\begin{array}{c}\text { Blood polyamines } \\
\text { (pmollml) }\end{array}$} \\
\cline { 2 - 4 } & fejunum & Small intestine & $182(76)$ \\
LA & $167(13)$ & $849(59)$ & $184(69)$ \\
LA + AG & $129(59)$ & $473(225)^{\star \star}$ & $273(36)$ \\
PHA & $280(49)^{\star \star}$ & $1430(116)^{\star \star}$ & $292(42)$ \\
PHA + AG & $335(42)^{\star \star}$ & $1493(218)^{\star \star}$ & $180(80)$ \\
Ad libitum & $78(4)$ & $576(121)$ & $183(82)$ \\
48 h fast & $150(24)^{\star \star}$ & $955(61)^{\star \star}$ & $149(31)$ \\
6 h re-fed & $148(27)^{\star \star}$ & $1015(39)^{\star \star}$ & $172(24)$ \\
12 h re-fed & $103(18)^{\star}$ & $647(63)$ &
\end{tabular}

Data are means (SD) for five rats per treatment.

LA, lactalbumin based control diet, containing $10 \%$ protein; PHA, kidney bean based diet, in which $5 \%$ of the lactalbumin was replaced by bean proteins, providing $42 \mathrm{mg} \mathrm{PHA} / \mathrm{rat}$ per day; AG, LA or PHA diets containing $6 \mathrm{mg}$ aminoguanidine/day. Rats in these groups were also injected intraperitoneally with $5 \mathrm{mg}$ aminoguanidine in saline every day for three days.

Significantly differences between LA or ad libitum: ${ }^{\star} \mathrm{p}<0.05$; ${ }^{\star \star} \mathrm{p}<0.01$.

energy and support the metabolic needs of the gut tissue.

The most revealing of our experiments was the fasting/refeeding model. It has long been established that during fasting the small bowel tissue polyamine pool decreases and the activity of ODC is reduced almost to the limit of detection. ${ }^{18242527}$ When animals are fed after a period of fasting, ODC activity in the small intestinal epithelium is induced followed almost immediately by an increase in tissue polyamine content, ${ }^{182427}$ as was also found in the present experiment (table 3). However, in fasted rats, in spite of a decrease in tissue putrescine concentrations of the small intestine, the uptake of putrescine (or uptake of counts originating from putrescine) from the circulation via the basolateral side of the small bowel was highly significantly increased, with more than $80 \%$ immediately converted to succinate and only traces retained as putrescine (table 2). After refeeding and in parallel with the increase in putrescine content (when the gut was supplied with food-derived energy), the putrescine uptake slowly returned to normal and less was converted to succinate. Bamba et $a l^{18}$ reported that intestinal DAO activity was higher in fasted than in ad libitum fed rats, and this may also support our idea that putrescine is used as an energy source. It is generally accepted that, in fasted animals, the proliferative activity of most tissues is decreased, so it is possible that putrescine can be made available via the systemic circulation to provide fast metabolisable energy to the gut during deprivation. The proportion of this to the total energy pool is not clear at the moment, but while in ad libitum fed rats about $33 \%$ of the putrescine is converted to succinate, this amount represents $3 \%$ of the total succinate pool (44 of $1475 \mathrm{nmol}$ ) in the jejunum. In fasting animals, $88 \%$ of the putrescine is converted to succinate, and, although there is a reduction in tissue putrescine content, nearly twice the amount (77 $\mathrm{nmol}$ ) of the succinate pool is provided by putrescine. This is at least $15-20 \%$ of the tissue succinate pool, which is also replenished by fasting.

Putrescine can also help to initiate the growth process. When animals are fed on a diet containing the lectin PHA, fully reversible dose-dependent growth of the small intestine is induced. ${ }^{17}{ }^{21}$ In rats, PHA is able to double the weight of the small bowel in three days by increasing crypt cell production rate. ${ }^{28}$ PHA also stimulates rapid transport of polyamines from the blood circulation into gut tissue undergoing hyperplasia. ${ }^{17} 26$ Thus large amounts of polyamines accumulate in the stimulated cells before actual onset of growth is observed. ${ }^{17}{ }^{26}$ When we used the PHA model, uptake of putrescine from the basolateral side was stimulated within 60 minutes of growth initiation (tables 1 and 2), although the luminal uptake of putrescine was not altered. ${ }^{17}$ PHA also causes a massive uptake of amino acids and energy-producing molecules from the lumen of the gut to satisfy its energy requirement. ${ }^{29} 30$ However, the uptake of putrescine from the gut lumen to the intestinal tissue depends on gastric emptying, small bowel transit, and putrescine concentration of the small bowel mucosa. Putrescine can be taken up by passive diffusion, apical transport, and the paracellular route. From these experiments it is impossible to distinguish between these three routes. If putrescine was used to fuel the first phase of the growth process, this would explain the initial stimulation of basolateral putrescine uptake by the rat small intestine, which appeared to be coincident with a temporary increase in serum putrescine concentrations. ${ }^{31}$ As PHA also stimulates the uptake of amino acids and energy-producing molecules, energy derived from putrescine was therefore no longer needed. By the third day of PHA treatment, tissue putrescine content was significantly elevated (table 3 ), and the radioactivity recovered as putrescine was reduced (table 2). This could be explained by the reduction of DAO activity. ${ }^{16}$ Not surprisingly, in the presence of the DAO inhibitor AG, less putrescine was taken up from the circulation via the basolateral membrane into the small bowel (table 1), tissue putrescine content was much higher (table 3), and practically all the label was recovered in the putrescine form, supporting the role of DAO in the formation of all the succinate (table 2). Our data indicate that, when growth of the small bowel is just beginning, the first response to the growth signal in addition to induction of ODC ${ }^{7-15} 242527$ is the increase in putrescine uptake from the circulation via the basolateral membrane. ${ }^{17}{ }^{26}$ This putrescine can be quickly converted to succinate. Inhibition of DAO might lead to increased putrescine content, as suggested by Bamba et al. ${ }^{18}$ and Sessa et al. ${ }^{16}$ A putrescine uptake/transport system located in the basolateral membrane of the rabbit small intestine has recently been described by Milovic et al. ${ }^{32}$

Ornithine $\alpha$-ketoglutarate (OKG), increases the GABA content of the intestinal mucosa, ${ }^{15}$ suggesting that the OKG induced intestinal growth is related to the conversion of OKG to putrescine and to GABA, with the involvement of DAO metabolising putrescine to GABA. The use of putrescine as an energy source is in good agreement with these data. Although Raul et $a l^{15}$ suggested that, during adaptive 
hyperplasia, GABA formed from OKG regulates the growth of the intestinal mucosa via putrescine and GABA, we suggest that, in addition to GABA formation, there is further oxidation of putrescine to succinate to be used as energy. However, whether it is as GABA or succinate needs further studies. These views oppose the idea that the main function of putrescine in the small bowel is to serve as a precursor for the synthesis of spermidine and spermine.

In conclusion, we found that the uptake of putrescine from the circulation through the basolateral membrane and conversion of 30\% of putrescine transported across the basolateral membrane to succinate is an ongoing process in the healthy gut, but one that can be inhibited by AG. In fasting rats both putrescine uptake from the circulation and conversion to succinate by the small bowel mucosa is significantly increased (from 30 to $80 \%$ ). Our experiments have identified a novel function for putrescine in gut metabolism as an instant energy source in times of energy deficiency, supporting the metabolic needs of the gut tissue and helping to maintain its function in rats.

This work forms a part of the European Concerted Action Programme, AAIR 569/92, and was supported by the Scottish Office Agriculture, Environment and Fisheries Department.

1 Jänne J, Pösö H, Raina A. Polyamines in rapid growth and cancer. Biochim Biophys Acta 1978;473:241-93.

2 Pegg AE. Recent advances in the biochemistry of polyamines in eukaryotes. Biochem $f_{1986 ; 234: 249-62}$

3 polyamines in eukaryotes. Biochem f 1986;234:249-62. 53:747-90.

4 Marton L, Morris D. Molecular and cellular functions of the polyamines. In: McCann PP, Pegg A, Sjoerdsma A, eds. Inhibition of polyamine metabolism. San Diego: Academic Press, 1987:79-105.

5 Heby O, Persson L. Molecular genetics of polyamine synthesis in eukaryotic cells. Trends Biochem Sci 1990;15 153-8.

6 Bardocz S. Polyamines in tissue regeneration. In: Bachrach $\mathrm{U}$, Heimer YM, eds. The physiology of polyamines, Vol I. Boca Raton: CRC Press, 1989:95-106.

7 Seidel ER, Haddox MK, Johnson LR. Ileal mucosal growth during intraluminal infusion of ethylamine or putrescine. Am F Physiol 1985;249:G434-8.

8 Ginty DD, Osborne DL, Seidel ER. Putrescine stimulates DNA synthesis in intestinal epithelial cells. Am F Physiol 1989;257:G145-50.

9 Johnson LR. Regulation of gastrointestinal mucosal growth Physiol Rev 1988;68:456-502.

10 Luk GD, Baylin SB. Ornithine decarboxylase in intestinal maturation, recovery and adaptation. In: Robinson JWL maturation, recovery and adaptation. In: Robinson JWL,
Dowling RH, Reiken EO, eds. Mechanism of intestinal adaptation. Lancaster: MTP Press, 1982:65-78.

11 Luk GD, Baylin SB. Polyamines and intestinal growth: increased polyamine biosynthesis after jejumectomy. $A m \mathcal{F}$ Physiol 1983;245:G656-60.

12 Hosomi M, Stace NH, Lirussi F, et al. Role of polyamines in intestinal adaptation in the rat. Eur $\mathcal{f}$ Clin Invest 1987;17:375-85.
13 Jänne J, Hölttä E. Putrescine metabolizing enzyme activities in some rat tissues during postnatal development. Acta Chem Scand 1973;27:2399-404.

14 Goodlad RA, Gregory H, Wright NA. Is polyamine synthesis involved in the proliferative response of the intestinal epithelium to urogastrone-epidermal growth factor? Clin Sci (Colch) 1989;76:595-8.

15 Raul F, Gosse F, Galluser M, et al. Functional and metabolic changes in intestinal mucosa of rats after enteral administration of ornithine $\alpha$-ketoglutarate salt. FPEN $\mathcal{f}$ Parenter Enteral Nutr 1995;19:145-50.

16 Sessa A, Tunici P, Ewen SWB, et al. Diamine and polyamine oxidase activities in phytohaemagglutinin-induced growth of rat small intestine. Biochim Biophys Acta 1995;1244:198202.

17 Bardocz S, Brown DS, Grant G, Pusztai A. Luminal and basolateral polyamine uptake by rat small intestine stimulated to grow by Phaseolus vulgaris lectin phytohaemagglutinin in vivo. Biochim Biophys Acta 1990;1034:46mag.

18 Bamba T, Vaja S, Murphy GM, Dowling RH. Effect of fasting and feeding on polyamines and related enzymes along the villus:crypt axis. Digestion 1990;46:424-9.

19 Luk GD, Yang P. Distribution of polyamines and their biosynthetic enzymes in intestinal adaptation. Am f Physiol 1988;254:G194-200.

20 D'Agostino L, D'Argenio G, Ciacci C, et al. Diamine oxidase in rat small bowel: distribution in different segments and cellular location. Enzyme 1984;31:217-20.

21 Bardocz S, Grant G, Ewen SWB, et al. Reversible effect of phytohaemagglutinin on the growth and metabolism of rat gastrointestinal tract. Gut 1995;37:353-60.

22 Seiler N, Knödgen B. High-performance liquid chromatography procedure for the simultaneous determination of natural polyamines and their monoacetyl derivatives. $f$ Chromatogr $A$ 1980;221:227-35.

23 Womersley C, Drinkwater K, Crowe JH. Separation of tricarboxylic acid cycle acids and other related organic acids in insect hemolymph by high-performance liquid chromatography. f Chromatogr A 1985;318:112-16.

24 Fujimoto K, Granger DN, Johnson LR, et al. Circadian rhythm of ornithine decarboxylase activity in small intestine of fasted rats. Proc Soc Exp Biol Med 1992;200: 409-13.

25 Alarcon P, Lin CH, Lebenthal E, Lee PC. Interaction of malnutrition and difluoromethylornithine-induced intestinal mucosal damage: degree of severity and subsequent recovery. Digestion 1988;41:68-77.

26 Bardocz S. The role of basolateral polyamine uptake in intestinal adaptation. In: Dowling RH, Fölsch UR, Löser $\mathrm{C}$, eds. Polyamines in the gastrointestinal tract. Dordrecht: Kluwer Academic Publishers, 1992:409-16.

27 Baer AR, Cheeseman CI, Thomson ABR. Substrate specificity in the stimulation of intestinal ornithine decarboxylase activity by refeeding after starvation. Biochim Biophys Acta 1987;924:257-9.

28 Banwell JG, Howard R, Kabir I, et al. Small intestinal growth caused by feeding red kidney bean phytohaemagglutinin lectin to rats. Gastroenterology 1993;104:1669-77.

29 Pusztai A, Ewen SWB, Grant G, et al. Stimulation of growth and polyamine accretion in the small intestine and pancreas by lectins and trypsin inhibitor. In: Dowling RH, Fölsch UR, Löser C, eds. Polyamines in the gastrointestinal tract. Dordrecht: Kluwer Academic Publishers, 1992:47383.

30 Pusztai A. Plant lectins. Cambridge: Cambridge University Press, 1991.

31 Bardocz S, Grant G, Brown DS, et al. Involvement of polyamines in Phaseolus vulgaris lectin induced growth of polyamines in in vivo. Med Sci Res 1989;17:309-11.

32 Milovic V, Stein J, Piiper A, Gerhard R, Zeuzem S, Caspary WF. Characterization of putrescine transport across the intestinal epithelium: study using isolated brush-border and basolateral membrane-vesicles of the enterocyte. Eur $\mathcal{F}$ Clin Invest 1995;25:97-105. 